\title{
Bicondylar Angle and its Relation with Length and Neck Length of Human Femur
}

\author{
Rabita Kharbuja, ${ }^{\mathrm{a}, \mathrm{b}}$ Rashmi Manjushree Adhikari, ${ }^{\mathrm{a}, \mathrm{b}}$ Anupama Shrestha ${ }^{\mathrm{a}, \mathrm{c}}$
}

\begin{abstract}
:
Introduction: Femoral bicondylar angle has immense importance from anatomical and clinical (forensic and anthropometric) point of view and is the characteristic feature of bipedal gait in humans. It is the angle between axis of femoral shaft and a line perpendicular to its transcondylar axis. The study was carried out to assess bicondylar angle and its relationship with femur length and neck length. Methods: Bicondylar angle, length, and neck length of available dry human femurs of unknown sex and age were measured using osteometric board and vernier caliper. Bicondylar angle between two sides were compared. Similarly, relation between the angle and femoral length and length of femoral neck was studied. Result: Bicondylar angle on right side was $8.65^{\circ}(S D=2.03)$ and on left side was $9.35^{\circ}(S D=2.05)$ and the different was not statistically significant $(p=0.08)$. On both sides, no significant correlation was found between bicondylar angle with femoral length and length of femoral neck. Conclusion: Mean bicondylar angle of right femur was $8.65^{\circ}$ and that of left was $9.35^{\circ}$ and the difference was not statistically significant. There was no significant relation between the angle and other two parameters.
\end{abstract}

Keywords: bicondylar angle $\bullet$ femoral condyles $\bullet$ femoral length $\bullet$ femoral neck

\section{INTRODUCTION:}

Femoral bicondylar angle is defined as the angle between femoral shaft axis and a line perpendicular to the infracondylar plane. Modern human skeleton has many key traits for bipedal locomotion and bicondylar angle is one of them. [1] Ontogenetically, bicondylar angle forms when the femur grows in early childhood. At birth, the shaft axis of femur is perpendicular to the methaphyseal growth plate. The angle is formed when the child first starts to walk and reaches a stable value of eight to ten degrees by the age

a - Lecturer, Department of Anatomy

b - Lumbini Medical College, Palpa, Nepal

c - Kathmandu University School of Medical Sciences, Kavre, Nepal

\section{Corresponding Author:}

Rabita Kharbuja

e-mail: rabbi_kha@yahoo.com

ORCID: https://orcid.org/0000-0001-8786-4829

\section{How to cite this article:}

Kharbuja R, Adhikari RM, Shrestha A. Bicondylar angle and its relation with length and neck length of human femur. Journal of Lumbini Medical College. 2018;6(1):17-20. DOI: 10.22502/jlmc. v6i1.176. Epub: 2018 May 24. of eight years.[2] Bicondylar angle does not form in bedridden children (neuromuscular disorders, paraplegic) who cannot walk in early stage of childhood.[3] In contrast, quadrupedal apes have small bicondylar angles.[4]

Bicondylar angle unambiguously implies bipedalism so a fossil femur is sufficient for paleoanthropologist to determine the human lineage. Besides, determining bicondylar angle is useful for both the anatomist as well as orthopedic surgeons for their clinical practices.

This study aims to determine femoral bicondylar angle and observe any variation on right and left side, and also to assess its relation with length of femur and length of neck of femur available at Anatomy Department.

\section{METHODS:}

A cross-sectional study was carried out in all dry adult human femurs available in the Department of Anatomy, Institute of Medicine, Kathmandu. Fully ossified bones irrespective of age, sex, and races were included. Bones with gross asymmetry or deformity were rejected. 


\section{Measurement of bicondylar angle:}

We adopted the method formulated by Heiple KG. et al. and shown in Figure 1A and Figure 1B.[4] The femur was placed with posterior aspect of femoral condyles and greater trochanter touching the horizontal surface on an osteometric board, on which a paper sheet was fixed. The inferior margin of both the condyles was placed against the vertical surface of the osteometric board (line Z). Infracondylar plane was taken as plane of the vertical plate and a horizontal line was drawn on the paper. At a level of about one-fourth of the standard maximum length of femur from its distal end, two points were marked on the paper, using verniercaliper (point X). Similarly two other points were marked on the paper showing maximum diameter of shaft just below the lesser trochanter (point Y). The axis of shaft was obtained by a line joining the middle points of diameters at points $\mathrm{X}$ and $\mathrm{Y}$, and was prolonged to meet the infracondylar plane represented by horizontal line $Z$. The angle between the axis of shaft and the perpendicular line to the infracondylar plane denotes the bicondylar angle.

\section{Measurement of femoral neck length:}

It was measured as distance between inferior region of base of femoral head and lower end of intertrochanteric line with the help of Vernier caliper as shown in Figure 2.[5]
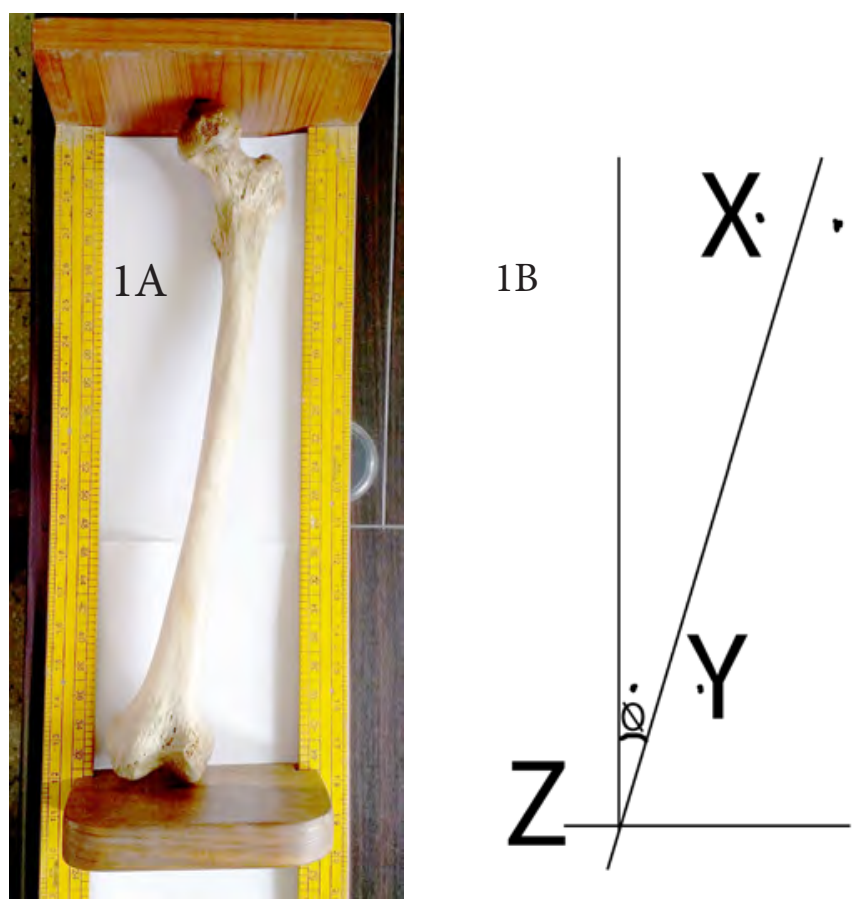

Fig 1A, 1B: Measurement of femoral bicondylar angle with osteometric board

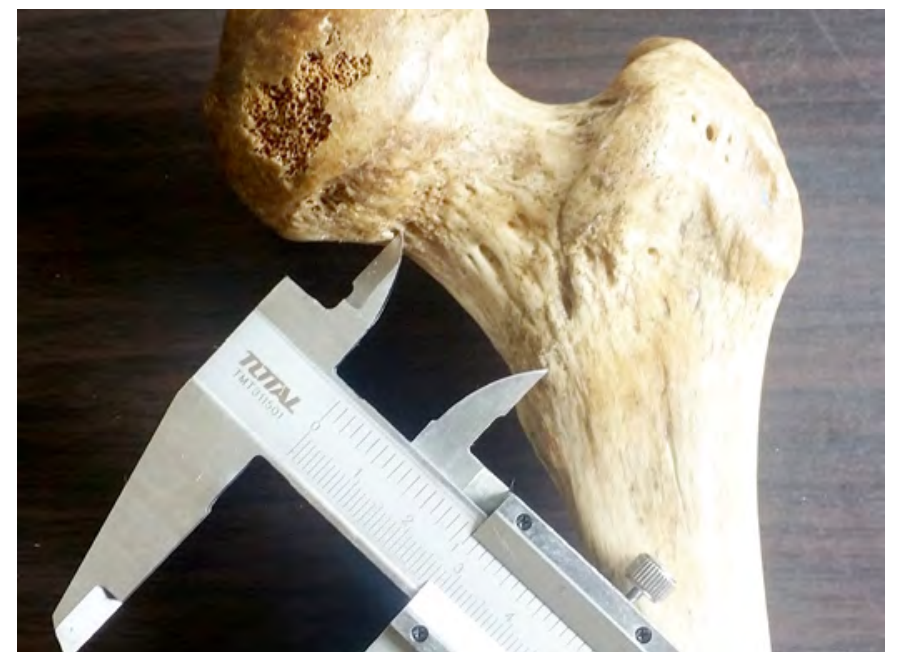

Fig 2: Measurement of femoral neck length

\section{Data Analysis:}

Data were entered in SPSS (Statistical package for Social studies) software, version 16. Descriptive statistic was presented as frequency, mean, and standard deviation. Independent sample t-test was used to compare mean bicondylar angle between right and left femur. Pearson correlation was used to determine relationship between bicondylar angle and other femur dimensions (length and neck length). $P$ value less than 0.05 was considered significant.

\section{RESULTS:}

A total of 102 dry adult human femur were available for the study. There were 51 (50\%) right femur and 51 (50\%) left femur. The morphometric parameters of dry femurs (maximum, minimum, mean and standard deviation) are presented in Table 1. The difference of bicondylar angle of two sides was not statistically significant $(t=-1.75, d f=100, p=$ 0.08).

Pearson correlations were measured to determine the relationship among bicondylar angle and femoral dimensions (Fig 3A, Fig 3B, Fig 3C, Fig 3D). None of the parameters were statistically significantly correlated as shown in Table 2.

Table 1: Morphometric parameters of dry femurs

\begin{tabular}{|ccccc}
\hline Variables & Min & Max & Mean & SD \\
\hline Right femur length $(\mathrm{cm})$ & 37 & 47 & 42.13 & 2.64 \\
\hline Right neck length $(\mathrm{cm})$ & 2 & 4 & 3.08 & 0.47 \\
\hline Right Bicondylar angle & $5^{\circ}$ & $13^{\circ}$ & $8.65^{\circ}$ & 2.03 \\
\hline Left femur length $(\mathrm{cm})$ & 38 & 48 & 42.43 & 2.40 \\
\hline Left neck length $(\mathrm{cm})$ & 3 & 5 & 3.30 & 0.48 \\
\hline Left Bicondylar angle & $4^{\circ}$ & $14^{\circ}$ & $9.35^{\circ}$ & 2.05 \\
\hline
\end{tabular}




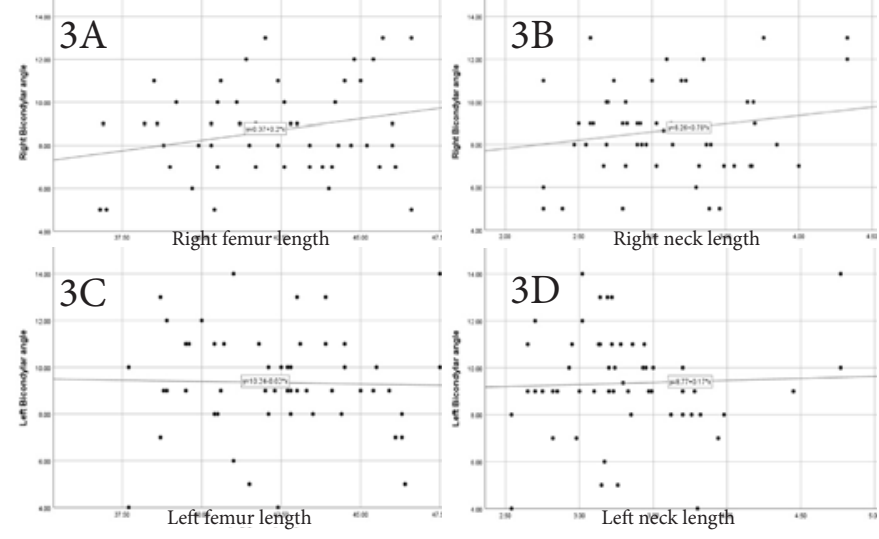

Fig 3: Scatter plots showing weak correlation between right bicondylar angle and right femur length (3A), right bicondylar angle and right neck length (3B), left bicondylar angle and left femur length (3C), left bicondylar angle and left neck length (3D)

Table 2: Pearson correlations between bicondylar angle and other femur parameters

\begin{tabular}{lcc}
\hline Pairs & $\boldsymbol{r}$ & $\boldsymbol{p}$ \\
\hline $\begin{array}{l}\text { Right femur length and } \\
\text { Right bicondylar angle }\end{array}$ & 0.15 & 0.31 \\
$\begin{array}{l}\text { Right neck length and } \\
\text { Right bicondylar angle }\end{array}$ & 0.04 & 0.78 \\
$\begin{array}{l}\text { Left femur length and } \\
\text { Left bicondylar angle }\end{array}$ & -0.23 & 0.11 \\
$\begin{array}{l}\text { Left neck length and } \\
\text { Left bicondylar angle }\end{array}$ & 0.19 & 0.18 \\
\hline
\end{tabular}

\section{DISCUSSION:}

We conducted this study to determine femoral bicondylar angle and observe any variation on right and left side, and also to assess its relation with femur dimensions. We found that right bicondylar angle was higher than left but the difference was not statistically significant $(p=0.08)$. There were no significant relationships between bicondylar angle with other femur dimensions (length and neck length).
Various studies had been carried out on assessment of femoral bicondylar angle and its correlation with various femoral dimensions. Table 3 shows the comparison of mean bicondylar angle of present study with other studies.

Mean bicondylar angle of left femur was found to be slightly higher than that of right side in most of the studies. Similar was the case in our study with mean bicondylar angle on left femur $9.35^{\circ}$, slightly higher than that of right femur $8.65^{\circ}$. But the side difference of bicondylar angle was not proved to be statistically significant in any of the study.[6,7,8,9,10,11]

Pandya et al., Ukoha et al., and Jyothi et al. found the bicondylar angle to be statistically higher in female compared to that of male on both sides which they believed to be because of wider pelvis in female.[6,8,10] Whereas, the studies carried by Mahajan et al., Sharma et al., and Biswas et al. did not find the gender difference of bicondylar angle. $[7,9,11]$

Jyothi et al. found bicondylar angle to have strong negative correlation with femur length hypothesizing that larger the bicondylar angle, lesser will be the femoral length.[10] Likewise, in this study bicondylar angle of left femur was negatively correlated with the femur length and femoral neck length although the finding was not statistically significant.

Although this study comply with other studies on having greater but not significant bicondylar angle in left femur compared to right, further research has to be undertaken on larger sample size, different race, regions, age, and sex. With further workup, bicondylar angle may be developed as a tool for sex determination.

Table 3: Comparison of mean bicondylar angle from different studies

\begin{tabular}{|c|c|c|c|c|c|c|c|}
\hline \multirow{2}{*}{ Authors } & \multirow{2}{*}{ Year } & \multirow{2}{*}{ Region } & \multicolumn{2}{|c|}{ Right (Mean, SD) } & \multicolumn{2}{|c|}{ Left (Mean, SD) } & \multirow{2}{*}{ Remarks } \\
\hline & & & Male & Female & Male & Female & \\
\hline Pandya et al.[6] & 2008 & Gujarat & $8.88^{\circ}(2.05)$ & $10.5^{\circ}(2.42)$ & $8.76^{\circ}(2.24)$ & $\begin{array}{l}10.83^{\circ} \\
(1.94)\end{array}$ & $\begin{array}{l}\text { Gender difference } \\
\text { significant }\end{array}$ \\
\hline Mahajan et al.[7] & 2011 & Punjab & $8.17^{\circ}(2.31)$ & $8.82(2.17)$ & $7.89^{\circ}(2.23)$ & $8.57^{\circ}(2.19)$ & Not significant \\
\hline Ukoha et al.[8] & 2011 & Nigeria & $8.35(0.24)$ & $8.16(0.81)$ & $8.66(0.23)$ & $8.91(0.18)$ & $\begin{array}{l}\text { Gender difference } \\
\text { significant }\end{array}$ \\
\hline Sharma et al.[9] & 2014 & Gwalior & $6.371(1.82)$ & $8.21(2.11)$ & 7.348 (2.37) & $8.729(2.30)$ & Not significant \\
\hline Jyothi et al.[10] & 2015 & South India & $7.26(1.67)$ & $8.71^{\circ}(1.58)$ & $7.39^{\circ}(1.40)$ & $8.96^{\circ}(1.49)$ & $\begin{array}{l}\text { Gender difference } \\
\text { significant }\end{array}$ \\
\hline Biswas el al.[11] & 2017 & West Bengal & $9.74(1.64)$ & $9.29(2.03)$ & $10.44(1.96)$ & $10.34(1.94)$ & Not significant \\
\hline Present study & 2018 & Nepal & \multicolumn{2}{|c|}{$8.65^{\circ}(2.03)$} & \multicolumn{2}{|c|}{$9.35^{\circ}(2.05)$} & Not significant \\
\hline
\end{tabular}




\section{CONCLUSION:}

Mean bicondylar angle was $8.65^{\circ}$ (SD = 2.03) and $9.35^{\circ}(S D=2.05)$ in right and left femur respectively and the difference was not statistically significant. There was no significant correlations between bicondylar angle and other femoral parameters.

\section{Acknowledgement:}

- Head of Department and faculty members of Department of Anatomy, Institute of Medicine.

- Prof. Rajani Shrestha.

- Department of Anatomy, Nepal Medical College and Lumbini Medical College.

\section{Conflicts of Interest:}

Authors declare that no competing interest exists.

\section{Funding:}

No funds were available.

\section{REFERENCES:}

1. Leakey MG, Feibel CS, McDougall I, Ward C, Walker A. New specimens and confirmation of an early age for Australopithecus anamensis. Nature. 1998;393(6680):6266. PMID: 9590689 DOI: $10.1038 / 29972$

2. Tardieu C, Trinkaus E. Early ontogeny of the human femoral bicondylar angle. Am J Phys Anthropol. 1994;95(2):183195. PMID: 7802095 DOI: $10.1002 /$ ajpa.1330950206

3. Tardieu C, Damsin JP. Evolution of the angle of obliquity of the femoral diaphysis during growth--correlations. Surg Radiol Anat. 1997;19(2):91-97. PMID: 9210242

4. Heiple KG, Lovejoy CO. The distal femoral anatomy of Australopithecus. Am J Phys Anthropol. 1971;35(1):75-84. PMID: 5003051 DOI: 10.1002/ajpa.1330350109

5. Ghosh I, Sengupta G, Basu P, Bose AD. Assessment of Relationship Between Neck Shaft Angle And Neck Length With Interepicondylar Distance In Femur. International Journal of Anatomy and Research 2015;3(4):1710-1715. DOI: 10.16965/ijar.2015.322

6. Pandya AM, Singel TC, Patel MM, Gohil DV. A Study of the Femoral Bicondylar Angle in the Gujarat Region. Journal of Anatomical Society of India. 2008;57(2):131134. Publisher Full Text
7. Mahajan A, Seema, Khurana BS, Gandhi D. Study of the Obliquity of the Shaft of the Femur in the Punjab Region. International Journal of Basic and Applied Medical Sciences. 2011;1(1):40-43. Publisher Full Text

8. Ukoha U, Oranusi C, Uzozie O, Okafor J, Ogugua P, Metu A. Radiological assessment of the femoral bicondylar angle in a Nigerian population. Tropical Journal of Medical Research. 2011;15(2):45-47. Publisher Full Text

9. Sharma RL, Sharma SK, Jehan M, Sastya A. Sexual dimorphism of the femoral bicondylar angle in Gwalior, Madhya pradesh region. International Journal of Healthcare and Biomedical Research. 2014;2(4):38-45. Publisher Full Text

10. Jyothi GL, Afroze KH, Yogesh C, V Pai, Lakshmiprabha S. Bicondylar angle of femur: An anthropometric study in South Indian population. Research Journal of Pharmaceutical, Biological and Chemical Sciences. 2015;6(4):1952-1959. Publisher Full Text

11. Biswas A, Bhattacharya S. A morphometric and radiological study of the distal end of femur in West Bengal population. Italian Journal of Anatomy and Embryology. 2017;122(1):39-48. Publisher Full Text 